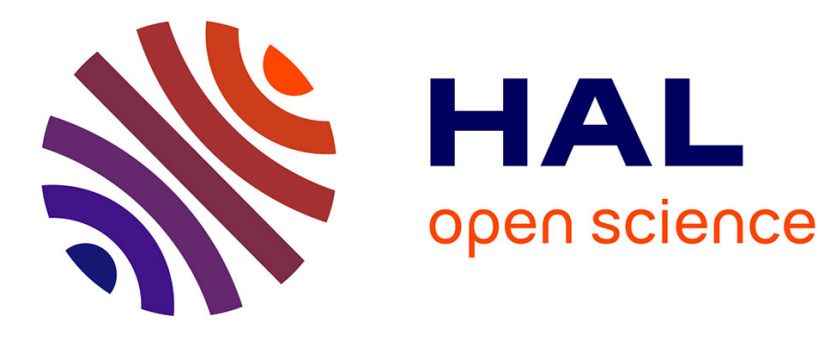

\title{
Coupling of quantum dots with a photon cage
}

Rémy Artinyan, Aziz Benamrouche, Chérif Belacel, Alice Berthelot, Pedro Rojo-Romeo, Romain Peretti, Bastian Gonzalez-Acevedo, Guillaume Beaudin, Vincent Aimez, Jean-Louis Leclercq, et al.

\section{- To cite this version:}

Rémy Artinyan, Aziz Benamrouche, Chérif Belacel, Alice Berthelot, Pedro Rojo-Romeo, et al.. Coupling of quantum dots with a photon cage. CLEO2014, Jun 2014, San Diego, United States. CLEO: Science and Innovations (CLEO_SI) 2014 paper: SM3M.3, 10.1364/CLEO_SI.2014.SM3M.3 . hal01016811

\section{HAL Id: hal-01016811 \\ https://hal.science/hal-01016811}

Submitted on 1 Jul 2014

HAL is a multi-disciplinary open access archive for the deposit and dissemination of scientific research documents, whether they are published or not. The documents may come from teaching and research institutions in France or abroad, or from public or private research centers.
L'archive ouverte pluridisciplinaire HAL, est destinée au dépôt et à la diffusion de documents scientifiques de niveau recherche, publiés ou non, émanant des établissements d'enseignement et de recherche français ou étrangers, des laboratoires publics ou privés. 


\title{
Coupling of quantum dots with a photon cage
}

\author{
R.Artinyan $^{1}{ }^{1}$, A.Benamrouche ${ }^{1}$, C.Belacel ${ }^{1-2}$, A.Berthelot ${ }^{2}$, P.Rojo-Romeo ${ }^{1}$, R.Peretti ${ }^{1}$, B.Gonzalez-Acevedo ${ }^{1}$, \\ G.Beaudin $^{3}$, V.Aimez ${ }^{3}$, J-L.Leclercq ${ }^{1}$, X.Letartre ${ }^{1}$, S.Callard ${ }^{1}$ \\ 1: Université de Lyon, Institut des Nanotechnologies de Lyon (INL), UMR CNRS 5270, Ecole Centrale de Lyon, 36 \\ avenue Guy de Collongue, F 69134 Ecully Cedex, France \\ 2 : Université de Lyon, Institut Lumière Matière (ILM), UMR CNRS 5306, Bâtiment Kastler, 10 rue Ada Byron \\ 69622 Villeurbanne Cedex, France \\ 3 : Institut Interdisciplinaire d'Innovation Technologique (3IT), Université de Sherbrooke, 3000 Boulevard Université, Sherbrooke, J1K OA5, \\ Québec, Canada \\ *Remy.artinyan@ec-lyon.fr
}

\begin{abstract}
We report on the investigation of the coupling between the high-Q mode of a tridimensional hollow silicon-based micro-resonator and $\mathrm{PbS}$ quantum dots in the near-infrared range, using near-field scanning optical microscopy and far-field spectroscopy.

OCIS codes: : (230.5750) Resonators; (230.5298) Photonic crystals; (230.3990) Micro-optical
\end{abstract}

Devices; (180.4243) Near-field microscopy.

\section{Introduction : design and fabrication of photon cages}

The general approach to achieve strong confinement of photons consists in high index contrast structuring of space at the wavelength scale. Numerous configurations have been used demonstrating the storage of light during a long time (high Q factor) into microcavities (small mode volume), leading to high Purcell effect. In particular, design and fabrication of multidimensional architectures for functional optical devices are of great interest for bio and health applications (such as sensing, fluorescence imaging) where it is aimed at strengthening the interactions with biological molecules or nanoparticles. For these sensing operations, hollow 3D resonators are ideal since they not only maximize the $3 \mathrm{D}$ light confinement but also enforce maximal overlap between the localized field and the environment (i.e. a potential volume of nanoparticles). Recently, we developed a new family of 3D photonic hollow resonators [1] which theoretically allows tight confinement of light in low-index media. The idea consists in using a very thin and highly reflective membrane made of a $1 \mathrm{D}$ or $2 \mathrm{D}$ photonic crystal in semiconductor material as a nonabsorbing broadband mirror. This effect, which has been demonstrated for 1D Fabry-Pérot cavities [2] is the keystone of the resonator principle. Simulations showed that reflectivity properties of these Photonic Crystal Mirrors (PCM) are well preserved with curvature radiuses up to a few $\mu \mathrm{m}$. We propose to "bend" the photonic membrane in air, in order to achieve cylindrical optical cavities. Numerical simulations showed that strong confinement of light is obtained in the central hollow part of the cylinder for relatively high Q modes ( 1400). In this work, we propose to exploit these properties to enhance light matter interaction by coupling an active material to the optical modes of the photon cage.
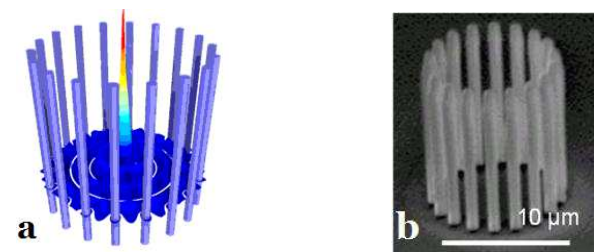

Fig. 1. Cylindrical photon cages : (a) electrical field map, (b) SEM image.

The photon cages consist in an array of 18 silicon pillars (height $10 \mu \mathrm{m}$, diameter $0,27 \mu \mathrm{m}$ ) periodically arranged on a $6 \mu \mathrm{m}$ diameter cylinder (Fig 1). The dimensions of the pillars, their numbers and the period of the PCM have been optimized to obtain a mode with a high quality factor and a strong confinement in the center of an empty cage (filled with air). Other sets of parameters have been found for a cage filled with low index media $(n \sim 1,5)$. Similar results are obtained in both cases for Q $(\sim 1400$ at $1560 \mathrm{~nm})$ and for the spatial characteristic of the mode (see Fig 1). For this mode, light is polarized along the axis of the cage and is confined in the horizontal plane by the mirror effect of the pillars array. Vertically, light does not propagate outside the cage and is mostly evanescent at the cage boundaries. We noticed that an extremely high concentration of the field is reached at the center of the cage although the cavity is composed of more than $95 \%$ of air (or low index material) [1]. 
Several photon cages have been fabricated by top-down manufacturing using high-aspect-ratio anisotropic etching through silicon-on-insulator (SOI) with $10 \mu \mathrm{m}$ device layer and $3 \mu \mathrm{m}$ buried oxide (BOX). This involved the use of $\mathrm{Cr} / \mathrm{SiO} 2$ submicron dots mask patterns prepared by e-beam lithography via spin coated negative electro-resist, plasma-enhanced chemical vapor deposition (PECVD), e-beam evaporation and a dedicated triple-cycling Deep RIE etching procedure [3].

\section{Activating the photon cages}

To probe photon cage efficiency in confining and enhancing light we chose to use internal emitters to excite the resonant modes of the structures directly. PbS colloidal quantum dots (QDs) have been selected as they present a broad and bright emission spectrum between $1.3 \mu \mathrm{m}$ and $1.7 \mu \mathrm{m}$, in the range of the photon cage modes. To observe the impact of the photon cage on the photoluminescence of the QDs, we used near-field scanning optical microscopy (NSOM) with an active tip to place the QDs in the evanescent part of the mode. For this a shear-force based NSOM [4] in collection mode was used to detect the near-field optical signal at the upper boundary of the photon cage. Prior to this measurement, the emitters were deposited at the apex of a metalized optical fiber tip to obtain an active probe. To avoid quantum dots emission blueshift (see Fig. 2.), the tip was passivated with a thin film of $\mathrm{Al}_{2} \mathrm{O}_{3}$. A 780 $\mathrm{nm}$ laser diode was focused on the tip to pump the QDs and their photoluminescence collected by the probe. We showed that the emitters were efficiently deposited on the near-field tip and that they exhibited a broad spectrum around $1,5 \mu \mathrm{m}$.

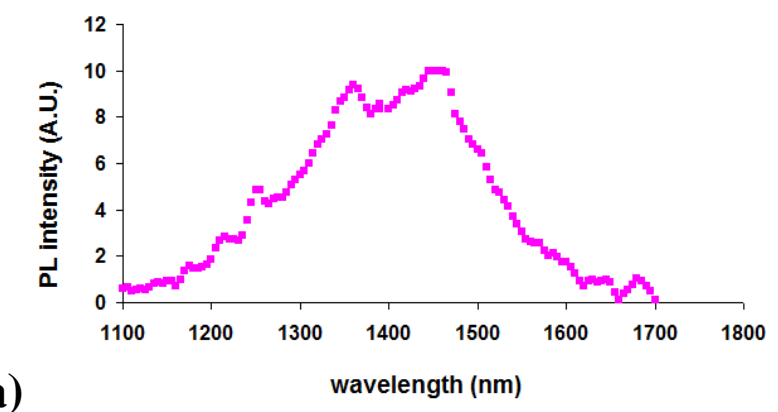

Fig. 2. Active NSOM probe : (a) photoluminescence (PL) spectrum

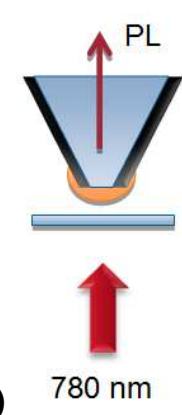

(b)

(b) mode collection setup.

To investigate the configuration of a photon cage filled with active material, we also embedded some with a $10 \mu \mathrm{m}$ thick layer of PDMS in which colloidal quantum dots of PbS are embedded. It showed that these structures are robust and can be immersed in a fluid without being damaged. Measurements are in progress to show the QDs photoluminescence modification by the photon cage modes.

\section{Conclusions and outlook}

We have designed new photonic microresonators showing very good confinement capability in low-index media, and have inserted a polymer matrix containing light emitters inside of them. The effect of the coupling of these light emitters with the photon cage modes will be presented during the communication. Other geometries of photon cages, such as helical or spherical structures, are also under study in our group [5]. The hollow core of photon cages could also host a microfluidic channel, thus providing a sensor with yet unseen overlapping between a strong electromagnetic fields and the analyte. Photon cages could also be used to efficiently trap particles, or as a lasing device.

\section{References}

[1] C.Sieutat et al, "Strong confinement of light in low index materials: the Photon Cage”, OPTICS EXPRESS Vol.21 - 17, $20015-20021$ (2013).

[2] S.Boutami et al., "Ultimate vertical Fabry-Perot cavity based on single-layer photonic crystal mirrors", OPTICS EXPRESS Vol.15 - 19 , $12443-12449(2007)$

[3] C.Sieutat et al, "3D harnessing of light with photon cage", Proceedings of SPIE Vol. 7712 77120E-1 (2010)

[4] TP. Vo et al., "Near-field probing of slow Bloch modes on photonic crystals with a nanoantenna" OPTICS EXPRESS Vol.20 - 4, 4124-4135 (2012)

[5] A.Danescu et al., "Spherical curves design for micro-origami using intrinsic stress relaxation”, Appl. Phys. Lett. 102-123111, 2013 